\title{
Preference for fixed over variable access to food
}

\author{
RONALD L. MENLOVE, HERB M. INDEN, and EDWARD G. MADDEN \\ University of Delaware, Newark, Delaware 19711
}

\begin{abstract}
Three pigeons pecked for food in a concurrent chain schedule. Pecks in one link of the concurrent chain resulted in a fixed duration of access to food, while pecks in the other link resulted in either no access to food or $8 \mathrm{sec}$ of access to food. All three pigeons pecked more often in the initial link which resulted in the fixed duration of access to food, indicating preference for fixed over variable access to food. This result does not seem consistent with previous results showing preference for variable- over fixed-interval schedules. However, the results are consistent if preference is determined by differential weighting of reward values, and preference is independent of whether a reward is fixed or variable. This analysis suggests that previous results of fixed-vs. variable-reward studies cannot be used to argue that animals do not prefer information over uncertainty.
\end{abstract}

The results of several experiments using concurrent chain schedules have shown that subjects prefer variable over fixed intervals between reinforcements (Davidson, 1969, 1972; Herrnstein, 1964; Hursh \& Fantino, 1973; Killeen, 1968; Navarick \& Fantino, 1974). This result has been interpreted as a preference for variable over certain rewards. Since the question of variable vs. certain rewards is closely related to the question of information vs. uncertainty, the variance preference interpretation has convinced some authors (cf. Mackintosh, 1974) that pigeons do not value a reduction in uncertainty. However, other authors have suggested that the choice for variableover fixed-interval schedules does not reflect a preference for variable reward. Rather, the preference for variable-interval schedules reflects a preference for short reinforcement delays (Killeen, 1968) or a preference for reduced times to reinforcement (Fantino, 1969). These latter authors suggest that the shorter interreinforcement intervals in the variable schedules are more heavily weighted in determining preference than the longer intervals in those schedules.

The present experiment used a concurrent chain schedule in a fixed- vs. variable-reward paradigm. However, the value of reward was manipulated by arranging different durations of access to food. It is possible that when variable durations of access to food are averaged, the weighting function is different from the weighting function obtained when variable intervals between rewards are averaged. If this possibility is true, and if preference is determined by the weighting function applied when variable rewards are averaged, then the results of the present experiment would be different from the results of previous studies comparing fixed- vs. variable-interval sched-

Send correspondence to: Dr. R. L. Menlove, Department of Psychology, 220 Wolf Hall, University of Delaware, Newark, Delaware 19711. ules. However, if preference is determined by variability, then the results of the present experiment would be similar to the results of the previous studies.

\section{METHOD}

Subjects

Three White Carneaux pigeons were maintained at approximately $80 \%$ of their free-feeding body weights. These subjects had not been used in previous experiments.

\section{Apparatus}

Each pigeon was trained in a separate three-key experimental chamber. The side keys of each chamber could be lighted white, and the center keys could be lighted either red or green. A digital computer assigned contingencies and recorded events simultaneously and independently in the three chambers.

\section{Procedure}

After keypeck training on an auto-shaping procedure similar to that described by Brown and Jenkins (1968), the pigeons pecked for food on a two-component concurrent chain schedule. In this schedule, the pigeons were allowed simultaneous access to two keys in the initial link. Pecks on either of these two keys were intermittently followed by access to one of two terminal links. Pecks in either of the terminal links were periodically followed by access to food.

Initial link. The initial link of the concurrent chain schedule was a synthetic concurrent schedule similar to that described in Menlove (1975, Experiment I). This schedule arranged transition to the terminal links contingent upon side keypecks. The parameters of the synthetic schedule were arranged to simulate a concurrent variable-interval $60-\mathrm{sec}$, variable-interval 60 -sec schedule. The minimum interreinforcement interval was $1 \mathrm{sec}$. Thus, the average initial-link duration was $30 \mathrm{sec}$, and approximately half of the terminal-link transitions were produced by left keypecks and approximately half by right keypecks. A changeover delay prevented transitions to the terminal links for $.5 \mathrm{sec}$ following a change from one side key to the other. Both side keys were lighted white during the initial link, and the center key was dark and inoperative.

Terminal links. Once a terminal-link transfer had been assigned, a peck on the appropriate side key produced one of two possible terminal-link stimuli. If a transfer was assigned to the left key and the pigeon pecked the left key, the center key was lighted red and the side keys became dark and inoperative. If a transfer was assigned to the right key and the pigeon pecked the right key, the center key was lighted green and the side keys became 
dark and inoperative. Once in either terminal link, the pigeons pecked for food on a fixed-interval 15 -sec schedule: $15 \mathrm{sec}$ after the terminal-link stimulus was first presented, the first center keypeck produced access to the food hopper. The duration of access to the food hopper in each of the two terminal links was changed from condition to condition and served as the independent variable in the experiment. At the end of each food-hopper presentation, the terminal link was ended, and the subject was returned to the initial link. The houselight was lighted in both the initial and terminal links whenever any pecking key was lighted, and each peck on a lighted key produced a 100 -msec feedback blackout of all lights.

Experimental conditions. To determine preference between fixed and variable access to food, a baseline was first established in which both terminal links provided a fixed 4-sec access to food. Since the terminal links in the baseline were the same, the baseline allowed an assessment of key bias in the initial link as well as a comparison point for the experimental conditions.

During the experimental conditions, the green terminal link provided variable access to food. On approximately half of the green terminal-link presentations, the reinforced keypeck was followed by 8-sec access to the food hopper; on the other half of the green terminal-link presentations, reinforcement was $.25-\mathrm{sec}$ access to the food hopper. The .25 -sec food-hopper presentation did not allow the pigeon any access to food, and was considered as $0 \mathrm{sec}$ access. However, the .25 -sec food-hopper presentation did provide a clear signal for the end of the terminal link. Thus, the expected access to food following the green terminal link was $4 \mathrm{sec}$ during each experimental condition.

Notice that it is possible to interpret the terminal link described above as providing variable access to food (as described) or as providing percentage reinforcement. The pigeon was rewarded on only $50 \%$ of the green terminal-link presentations. On the other $50 \%$ of the presentations, a signal (the $.25-\mathrm{sec}$ food-hopper presentation) indicated that food was not available. However, there is no evidence to suggest that percentage reinforcement is not one point on the continuum of variable amounts of access to food. Even if amount of access to food and percentage reinforcement are viewed as basically different procedures, the percentage reinforcement procedure would still be a variable-reward procedure, and the expected duration of access to food would still be 4 sec.
Thus, the logic of the experiment presented in the introduction would apply equally as well to percentage reinforcement as to variable durations of access to food.

Each reinforced keypeck in the red terminal link was followed by a fixed duration of access to food in a given experimental condition. However, the fixed duration of access to food was varied between 2 and 4 sec across experimental conditions. This parametric replication of the basic procedure provided a choice function which could be fitted by least squares techniques. This choice function, as well as Condition 2 in which the expected duration of access to food was the same on both alternatives, allowed the evaluation of preference between fixed vs. variable rewards.

To be certain that a reliable comparison point was available for the experimental conditions, the baseline was reestablished in the last condition of the experiment. The exact sequence of conditions is given in Table 1, which shows the duration of access to food following each terminal link and the number of sessions in each condition. Each daily session lasted for 50 terminal-link cycles during Conditions 1 through 3. However, to maintain the birds' body weights, the sessions were shortened to 40 terminal-link cycles during Condition 4 and 30 terminal-link cycles during Condition 5. A condition was terminated when the relative frequency of responding in the initial links did not appear to change in a systematic direction over the last 6 days of a condition.

\section{RESULTS}

The total number of responses on each key in each link and the total number of terminal-link presentations are shown in Table 1. Different numbers of daily sessions were used to construct the numbers shown in Table 1 to approximately equate the total number of terminal-link presentations contributing to a given data point. Thus, the numbers were summed over the last 4 days of Conditions 1 through 3, the last 5 days of Condition 4 , and the last 7 days of Condition 5. Table 1 also shows the arithmetic mean and standard deviation of the relative frequency of

Table 1

Summary of Procedure and Results

\begin{tabular}{|c|c|c|c|c|c|c|c|c|c|c|c|c|}
\hline \multirow{2}{*}{$\begin{array}{c}\text { Condi- } \\
\text { tion }\end{array}$} & \multirow{2}{*}{$\begin{array}{l}\text { Days of } \\
\text { Training }\end{array}$} & \multicolumn{2}{|c|}{$\begin{array}{c}\text { Duration of } \\
\text { Access to } \\
\text { Food* }\end{array}$} & \multirow[b]{2}{*}{ Bird } & \multicolumn{2}{|c|}{$\begin{array}{l}\text { Total } \\
\text { Initial-Link } \\
\text { Responding }\end{array}$} & \multicolumn{2}{|c|}{$\begin{array}{c}\text { Total } \\
\text { Terminal-Link } \\
\text { Responding }\end{array}$} & \multicolumn{2}{|c|}{\begin{tabular}{c}
\multicolumn{1}{c}{ Total } \\
Terminal-Link \\
Presentations
\end{tabular}} & \multicolumn{2}{|c|}{$\begin{array}{l}\text { Relative Frequency } \\
\text { of Responding on } \\
\text { the Left Key }\end{array}$} \\
\hline & & Red & Green & & Left & Right & Red & Green & Red & Green & Mean & SD \\
\hline 1 & 11 & 4 & 4 & $\begin{array}{l}1 \\
2 \\
3\end{array}$ & $\begin{array}{r}4674 \\
5950 \\
17296\end{array}$ & $\begin{array}{l}9364 \\
2540 \\
8781\end{array}$ & $\begin{array}{l}1350 \\
3317 \\
4097\end{array}$ & $\begin{array}{l}2239 \\
3605 \\
3483\end{array}$ & $\begin{array}{r}95 \\
98 \\
106\end{array}$ & $\begin{array}{r}105 \\
102 \\
94\end{array}$ & $\begin{array}{l}.34 \\
.48 \\
.67\end{array}$ & $\begin{array}{l}.04 \\
.09 \\
.09\end{array}$ \\
\hline 2 & 17 & 4 & $.25,8$ & $\begin{array}{l}1 \\
2 \\
3\end{array}$ & $\begin{array}{l}2617 \\
5325 \\
7297\end{array}$ & $\begin{array}{l}2579 \\
3447 \\
2918\end{array}$ & $\begin{array}{l}1761 \\
2114 \\
2413\end{array}$ & $\begin{array}{l}2510 \\
1657 \\
1929\end{array}$ & $\begin{array}{r}95 \\
105 \\
104\end{array}$ & $\begin{array}{r}105 \\
95 \\
96\end{array}$ & $\begin{array}{l}.51 \\
.61 \\
.72\end{array}$ & $\begin{array}{l}.03 \\
.04 \\
.02\end{array}$ \\
\hline 3 & 17 & 2 & $.25,8$ & $\begin{array}{l}1 \\
2 \\
3\end{array}$ & $\begin{array}{l}1738 \\
2599 \\
2630\end{array}$ & $\begin{array}{l}4250 \\
4240 \\
5796\end{array}$ & $\begin{array}{l}1930 \\
1210 \\
1927\end{array}$ & $\begin{array}{l}2302 \\
1218 \\
1174\end{array}$ & $\begin{array}{r}96 \\
103 \\
106\end{array}$ & $\begin{array}{r}104 \\
97 \\
94\end{array}$ & $\begin{array}{l}.29 \\
.38 \\
.31\end{array}$ & $\begin{array}{l}.03 \\
.05 \\
.01\end{array}$ \\
\hline 4 & 24 & 3 & $.25,8$ & $\begin{array}{l}1 \\
2 \\
3\end{array}$ & $\begin{array}{l}3346 \\
2836 \\
3534\end{array}$ & $\begin{array}{l}3220 \\
3703 \\
3622\end{array}$ & $\begin{array}{l}2324 \\
1793 \\
2079\end{array}$ & $\begin{array}{l}2670 \\
1890 \\
1539\end{array}$ & $\begin{array}{r}96 \\
102 \\
101\end{array}$ & $\begin{array}{r}104 \\
98 \\
99\end{array}$ & $\begin{array}{l}.51 \\
.43 \\
.49\end{array}$ & $\begin{array}{l}.02 \\
.02 \\
.03\end{array}$ \\
\hline 5 & 22 & 4 & 4 & $\begin{array}{l}1 \\
2 \\
3\end{array}$ & $\begin{array}{l}3074 \\
3399 \\
4810\end{array}$ & $\begin{array}{l}2935 \\
3589 \\
3425\end{array}$ & $\begin{array}{l}2730 \\
1756 \\
1994\end{array}$ & $\begin{array}{l}3195 \\
1992 \\
1412\end{array}$ & $\begin{array}{l}107 \\
115 \\
106\end{array}$ & $\begin{array}{r}103 \\
95 \\
104\end{array}$ & $\begin{array}{l}.51 \\
.49 \\
.58\end{array}$ & $\begin{array}{l}.07 \\
.03 \\
.06\end{array}$ \\
\hline
\end{tabular}

*In seconds. 


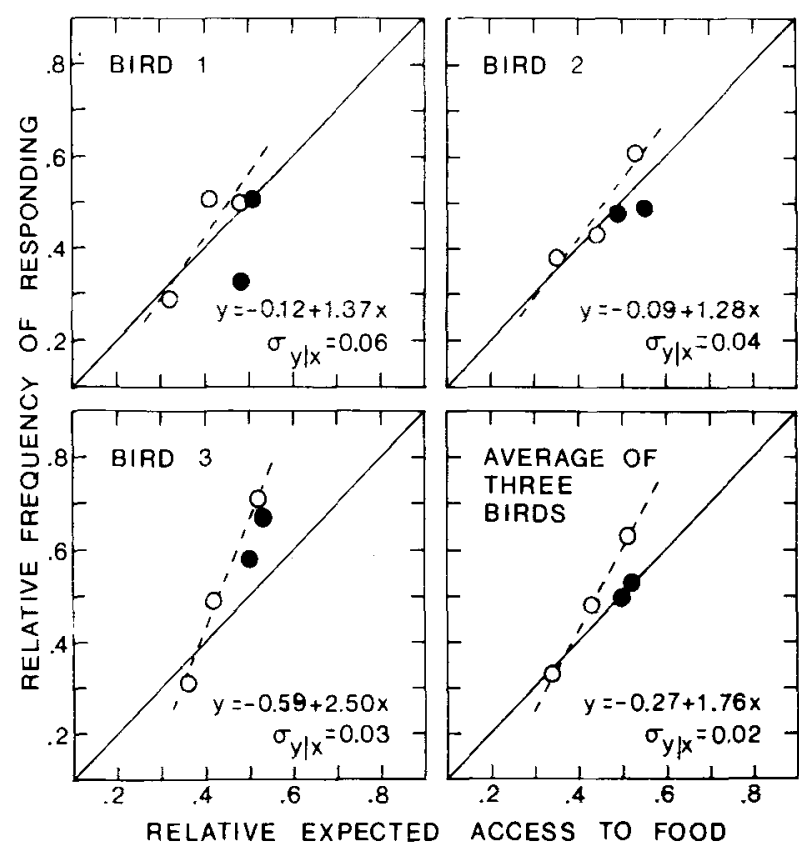

Figure 1. Relative frequency of responses on the left key in the initial link plotted against the relative expected access to food. The empty circles show data from conditions comparing fixed vs. variable access to food. The filled circles show data from baseline conditions comparing fixed vs. fixed access to food. The dashed line is a least-squares straight line fit to the empty circles. The parameters of this straight line are given at the lower right of each segment of the figure.

left key responses in the initial link over the last days of a condition.

The average relative frequency of left keypecks in the initial link of Condition 1 showed substantial departures from .5 in Birds 1 and 3. Thus, it would seem that there was substantial key bias in these two subjects. However, there was a large amount of variability in Condition 1, both within and between subjects. As a result of this variability, Condition 1 was replicated in Condition 5. Severe key bias was not observed in Condition 5 , and the average of Conditions 1 and 5 was used as a baseline to compare preference between fixed and variable access to food.

One measure of preference between fixed and variable access to food compared preference between the two 4-sec fixed alternatives from Conditions 1 and 5 with preference between the 4-sec fixed and 4-sec (expected) variable alternatives from Condition 2. Accordingly, Table 1 shows that for all birds the average relative frequency of left keypecks from Condition 2 was higher than the corresponding average from Conditions 1 and 5 . These differences were statistically significant ( $p<.05$ ) for Birds 2 and 3 but not for Bird $1[\mathrm{t}(13)=1.10,4.56$, and 2.67 for Birds 1, 2, and 3, respectively]. However, the difference between Condition 2 and the average of Conditions 1 and 5 , averaged over all three birds, was statistically significant at the .05 level $[F(1,41)=$
16.10]. Since the left key provided fixed access to food in Condition 2, the first measure of preference showed that Birds 2 and 3 preferred fixed over variable access to food.

A second measure of preference between fixed and variable access to food compared preference between the two 4-sec fixed alternatives from Conditions 1 and 5 with the least-squares function fitted to the results of the parametric replications in fixed vs. variable access to food from Conditions 2 through 4 . Figure 1 was constructed to facilitate this comparison and shows the relative frequency of left keypecks as a function of the relative expected access to food. The relative frequency of the left keypecks was obtained by dividing the total number of left keypecks from Table 1 by the total number of initial-link pecks. The relative expected access to food was constructed by first multiplying the duration of access to food from the red terminal link in a given condition by the total number of red terminal-link presentations in that condition. The resulting number gives the total amount of access to food in the red terminal links. Second, the average duration of access to food in the green terminal links, $4 \mathrm{sec}$, was multiplied by the total number of green terminal-link presentations in a condition. The resulting number is the expected access to food in the green terminal links. Finally, the amount of access to food in the red terminal links was divided by the sum of the amount of access to food in the red terminal links and the expected amount of access to food in the green terminal links. Figure 1 also shows the straight line fit to the data from Conditions 2 through 4 . The linear function has a slope greater than one for each of the three birds. In addition, the function was higher than the average relative frequency of left keypecks from Conditions 1 and 5 for all three birds. A test of the difference between the relative frequency of left keypecks predicted from the straight line at .5 relative expected access to food and the average of Conditions 1 and 5 was statistically significant $(p<.05)$ for each of the three subjects $[\mathrm{t}(22)=3.11,3.78$, and 4.80 for Birds 1, 2, and 3, respectively]. Thus, the second measure of preference shows that all three of the birds prefer fixed over variable access to food.

The data averaged over all three birds is also shown in Figure 1, as is the straight line fit to the average data. The average data were used to find a point of indifference between variable access to food and $4 \mathrm{sec}$ of fixed access to food. It was observed that the expected variable access to food required to produce indifference was $5.14 \mathrm{sec}$.

\section{DISCUSSION}

Two measures were presented to show preference between fixed vs. variable access to food. The first 
measure compared preference from a condition with only fixed access to food with preference from a condition with fixed vs. variable access to food. This measure showed that two of the three subjects preferred fixed over variable access to food. The second measure compared choice from a condition with only fixed access to food with a linear function fitted to a set of conditions with parametric replication of fixed vs. variable access to food. This latter measure showed that all three subjects preferred fixed over variable access to food. Thus, it was concluded that pigeons prefer fixed over variable access to food.

The conclusion that pigeons prefer fixed over variable access to food should not be taken as a demonstration of preference against variability. As noted in the introduction, a nonlinear preference function for amount of access to food would produce a similar result. That is, the present result would obtain if $8 \mathrm{sec}$ access to food was evaluated as less than twice the value of $4 \mathrm{sec}$ access to food. However, the present results do apply to the question of whether preference in a fixed-vs. variable-reward paradigm is determined more importantly by variability per se or by the weighting function applied when variable rewards are averaged.

Previous experiments have shown that pigeons prefer variable- over fixed-interval schedules (Davidson, 1969, 1972; Herrnstein, 1964; Hursh \& Fantino, 1973; Killeen, 1968; Navarick \& Fantino, 1974). If these previous results are taken as showing that pigeons prefer variable over fixed rewards, and the results of the present experiment are taken as showing that pigeons prefer fixed over variable rewards, the results are not consistent. However, if the results of the previous studies and the present experiment are taken as showing the weighting function applied when variable rewards are averaged, the results are quite consistent: One weighting function applies when variable intervals between rewards are averaged, and a different weighting function applies when variable amounts of access to food are averaged. A weighting function for variable intervals between rewards has been described and is adequate to explain the preference for variable- over fixed-interval schedules (Fantino, 1969). Since this weighting function has been shown to have good predictive validity in several situations, it is plausible that preference in the fixed- vs. variable-reward paradigm is not determined by variability per se.

The present analysis argues against the use of the pigeons' preference for variable- over fixed-interval schedules as evidence that pigeons do not value information. However, this preference is not the only empirical support for the argument that pigeons do not value information. Several experiments have shown that the stimulus that signals the less valued of two alternatives $\left(\mathrm{S}^{\Delta}\right)$ is aversive (Mulvaney, Dinsmoor, Jwaideh, \& Hughes, 1974; Terrace, 1971). Since it is presumed that information would have a positive value and $S \Delta$ carries as much information as any other stimulus, the negative value of $S^{\Delta}$ is generally regarded as showing that pigeons do not value information (Fantino, 1977). Thus, a convincing demonstration that pigeons value information would require a demonstration that information contributes to the value of $S^{\Delta}$.

Experiments on percentage reinforcement have also been used to argue that pigeons do not value information. Kendall (1974) used a concurrent chain schedule to study preference between $50 \%$ and $100 \%$ reinforcement. If matching between the relative frequency of responding and the relative density of reinforcement represents a baseline for the study of preference, Kendall showed that pigeons prefer $50 \%$ reinforcement over $100 \%$ reinforcement. Even greater preference for the variable reward was observed when stimuli signaled the availability of food on the variable alternative. Thus, Kendall's pigeons preferred an uncertain over a certain reward.

The present results are not consistent with Kendall's. The present experiment showed preference for the fixed, $100 \%$ reward. However, this lack of consistency may have been due to a peculiarity in Kendall's procedure. No responses were required in Kendall's terminal links. In fact, if responses occurred, they delayed the delivery of food for $2 \mathrm{sec}$. This terminal-link procedure is similar to a procedure that has been shown to automaintain keypecks in pigeons. If stimuli that precede food are presented on a pecking key, keypecking is observed even if keypecks postpone scheduled access to food (Williams \& Williams, 1969). If such automaintained keypecks occurred in Kendall's terminal links, they delayed access to food. The different stimulus conditions could interact with the automaintenance procedure to produce different levels of responding and consequently different delays in the different terminal links. These differences in delay to food would produce differences in preference for the terminal links. Thus, Kendall's results could be due entirely to the automaintenancelike procedure used in the terminal links. Using a more traditional concurrent chain procedure, the present experiment showed that pigeons prefer $100 \%$ reinforcement over $50 \%$ reinforcement.

\section{REFERENCES}

Brown, P. L., \& Jenkins, H. M. Auto-shaping of the pigeon's key peck. Journal of the Experimental Analysis of Behavior, $1968,11,1-8$.

Davison, M. C. Preference for mixed-interval versus fixedinterval schedules. Journal of the Experimental Analysis of Behavior, 1969, 12, 385-389.

Davison, M. C. Preference for mixed-interval versus fixedinterval schedules: Number of component intervals. Journal of the Experimental Analysis of Behavior, 1972, 17, 169-176. 
Fantino, E. Choice and rate of reinforcement. Journal of the Experimental Analysis of Behavior, 1969, 12, 723-730.

Fantino, E. Conditioned reinforcement: Choice and information. In W. K. Honig \& J. E. R. Staddon, Handbook of operant behavior. Englewood Cliffs, New Jersey: Prentice-Hall, 1977.

Herrnste in, R. J. Aperiodicity as a factor in choice. Journal of the Experimental Analysis of Behavior, 1964, 7, 179-182.

Hursh, S. R., \& Fantino, E. Relative delay of reinforcement and choice. Journal of the Experimental Analysis of Behavior, $1973,19,437-450$.

Kendall, S. B. Preference for intermittent reinforcement. Journal of the Experimental Analysis of Behavior, 1974, 21, 463-473.

KILleEN, P. On the measure of reinforcement frequency in the study of preference. Journal of the Experimental Analysis of Behavior, 1968, 11, 263-269.

Mackintosh, N. J. The psychology of animal learning. New York: Academic Press, 1974.

Menlove, R. L. Local patterns of responding maintained by concurrent and multiple schedules. Journal of the Experimental Analysis of Behavior, 1975, 23, 309-337.

Mulvaney, D. E., Dinsmoor, J. A., Jwaideh, A. R., \& Hughes, L. H. Punishment of observing by the negative discriminative stimulus. Journal of the Experimental Analysis of Behavior, 1974, 21, 37-44.

Navarick, D. J., \& Fantino, E. Stochastic transitivity and unidimensional behavior theories. Psychological Review, 1974, 81 , 426-442.

Terrace, H. S. Escape from S-. Learning and Motivation, $1971,2,148-163$.

Williams, D. R., \& Williams, H. Auto-maintenance in the pigeon: Sustained pecking despite contingent non-reinforcement. Journal of the Experimental Analysis of Behavior, 1969, 12, $511-520$.

(Received for publication May 23, 1978; (revision accepted March 7, 1979.) 